\title{
CARDIOMYOPATHY IN AFRICAN CHILDREN
}

\author{
BY \\ H. STEIN, ${ }^{*}$ M. H. SHNIER, ${ }^{+}$S. WAYBURNE, and C. ISAACSON $\div$ \\ From the Department of Paediatrics, Baragwanath Hospital, and University of Witwatersrand, Johannesburg \\ and the Department of Pathology, South African Institute for Medical Research and \\ Baragwanath Hospital, Johannesburg, S. Africa
}

(RECEIVED FOR PUBLICATION APRIL 17, 1964)

Much has been written about cardiac hypertrophy of unknown aetiology in African adults in the past 17 years. Bedford and Konstam (1946) described cases in West African soldiers, and Davies (1948) described 36 cases in East Africa; he stated that the condition was responsible for $10^{\circ}$ of the cases of heart failure in African adults in that area. Gillanders (1951) working at this hospital reported 30 clinically similar cases; these patients had low output cardiac failure with predominant left ventricular hypertrophy and at necropsy mural thrombi were found in 5 cases. There was no evidence of myocarditis but there was a fine fibrosis of the ventricular endocardium. He attributed the condition to malnutrition and termed it 'nutritional heart disease'. Becker, Chatgidakis, and van Lingen (1953) reported 40 patients in Johannesburg and demonstrated degeneration of the collagen and its associated ground and cement substances in the myocardium. While they proposed the term 'cardiac collagenosis', the cases in South Africa are now collectively named 'cryptogenic heart disease and account for $14 \%$ of all adult cases of congestive cardiac failure coming to necropsy (Higginson, Isaacson, and Simson, 1960). Gillanders (1951) thought that this condition might occur in children but did not describe cases. Altman and Stein (1956) described 4 such cases calling them 'Idiopathic Hypertrophy of the Heart in African Children'. During the past 5 years 23 African children have been seen at this hospital with cardiac failure of unknown origin: necropsies were carried out in over half the cases. We present an analysis of the 23 cases to illustrate that clinically, radiologically, and pathologically they are a relatively homogeneous group and to relate them to cardiomyopathies in children in other environments and to adults in South Africa.

- Present address: 216 Harley Chambers. Jeppe Street. Johannesburg.

+ Present address: 211 Lister Buildings. Jeppe Street. Johannesburg.

† Present address: 1206 Medical Centre. Jeppe Street, Johannesburg.

\section{Cases Studied}

All the cases are set out in the Table.

There were 13 boys and 10 girls and their ages ranged from 6 months to 7 years. Only 3 were under 1 year of age, and there was no family history of a similar affection in any. The state of nutrition of the patients varied considerably from case to case. Only one child, a girl of 4 years, showed the picture of severe malnutrition. She was admitted for malnutrition, and routine radiographs of the chest on admission showed clear lungs and a normal-sized heart. While in the ward she developed cardiac failure and hallucinations. A further radiograph at this time showed an enlarged heart (Fig. 1). Though she was clinically in low output cardiac failure, she was treated with large doses of thiamine for possible beriberi with no response. She died four months later and necropsy showed a typical picture of cardiomyopathy. In none of the other children was there anything to suggest that malnutrition was an aetiological factor, and thiamine was also administered to several without response. The children all suffered from clinical low output cardiac failure either on admission or during observation in the ward, and all had normal blood pressures. All except 3 (Cases 3,16 , and 21) had an atrial gallop rhythm and there was a striking absence of significant cardiac murmurs, though in 8 a very short, soft apical ejection systolic murmur was heard. The apex beat was poorly felt in all, but where ventricular dominance could be established clinically, it suggested left ventricular hypertrophy, which was confirmed by electrocardiograms in most instances (Fig. 2), there being $T$ wave inversion in all chest leads in 12 patients. Radiographs and fluoroscopy showed cardiomegaly and globular shape to the heart which pulsated very poorly and often suggested a pericardial effusion. However, in 11 cases where the pericardium was tapped, no fluid was obtainable. The vasculature of the lungs was normal. Hemiplegia in 4 children was 


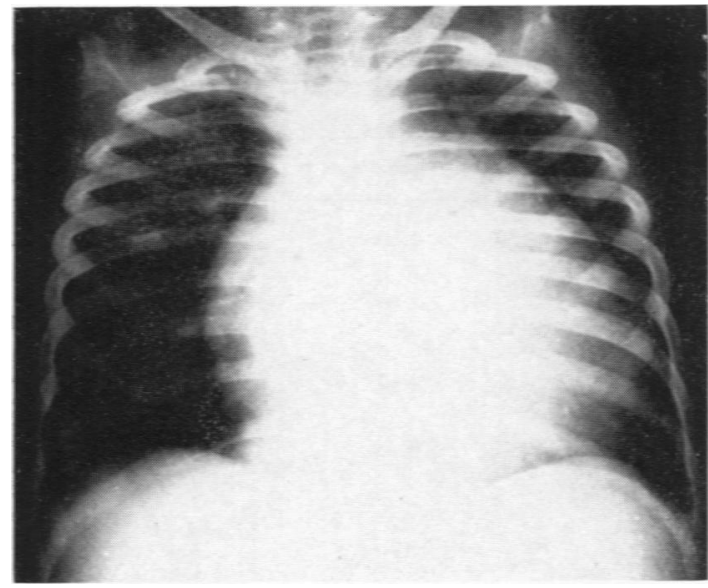

FK. 1.-Radiograph shouing typical cardiomegaly in a 4-year-old child.

due to embolic phenomena and in one of these frank haematuria was suggestive of renal embolism.

Viral studies, with a view to excluding Coxsackie myocarditis, were negative in all 20 cases studied. Skeletal muscle biopsy on 6 patients showed no excess of glycogen.

The time spent in hospital varied from 4 days to 9 months. One patient had two admissions of 3 months and 6 months and died during the second admission, while a further patient was admitted to hospital five times during a period of one and a half years. In all, 14 children died and necropsies were performed on 12 of them; of the remaining 9, 6 are still being observed as out patients, while 3 have failed to report and have been lost to follow-up. In none of the patients who recovered from congestive cardiac failure did the heart size return to normal: this suggests that the cardiomegaly is irreversible and that the ultimate prognosis is very poor.

\section{Pathology}

There were 12 children, 6 girls and 6 boys, who came to necropsy, at ages ranging from 6 months to 6 years. The heart weights ranged from one and a half to three and a half times the normal. Macroscopically there was usually hypertrophy and dilatation of both ventricles, the left predominating. Ante-mortem thrombi were present in the left ventricle in 6 , in the right ventricle in 2 , and in the right atrium in 1 patient. The atria were also dilated. There was fibrous thickening of the endocardium and this was most prominent in the left ventricle (Fig. 3): this was diffuse in some cases but tended to be more marked over some areas, particularly the apex of the left ventricle. Infarcts were present in 6 cases and were distributed amongst lungs, kidneys, spleen, and brain. There was no evidence of any associated congenital heart lesions and the foramen ovale was closed in all cases. Histologically, when the fibrous thickening was mild to moderate, it was composed of both collagen and elastic, the latter being most prominent adjacent to the myocardium (Figs. 4 and 5); when the endocardial thickening was marked collagen predominated. The thickened endocardium in most cases contained a sprinkling of lymphocytes and plasma cells with occasional neutrophils. The trabeculae carneae were often encased in fibrous tissue and the fibrous thickening usually involved the

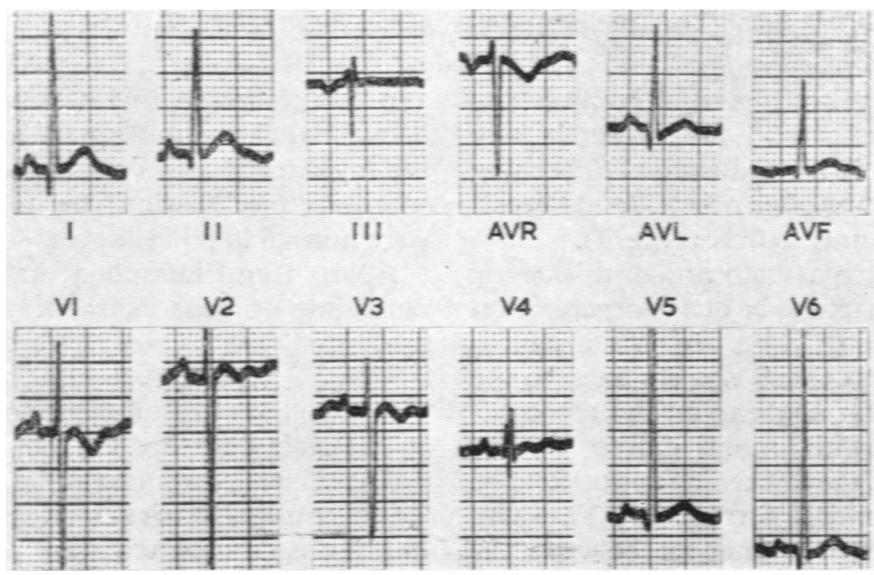

FiG. 2.-Electrocardiogram of a 3-year-old child showing left ventricular hypertrophy. 


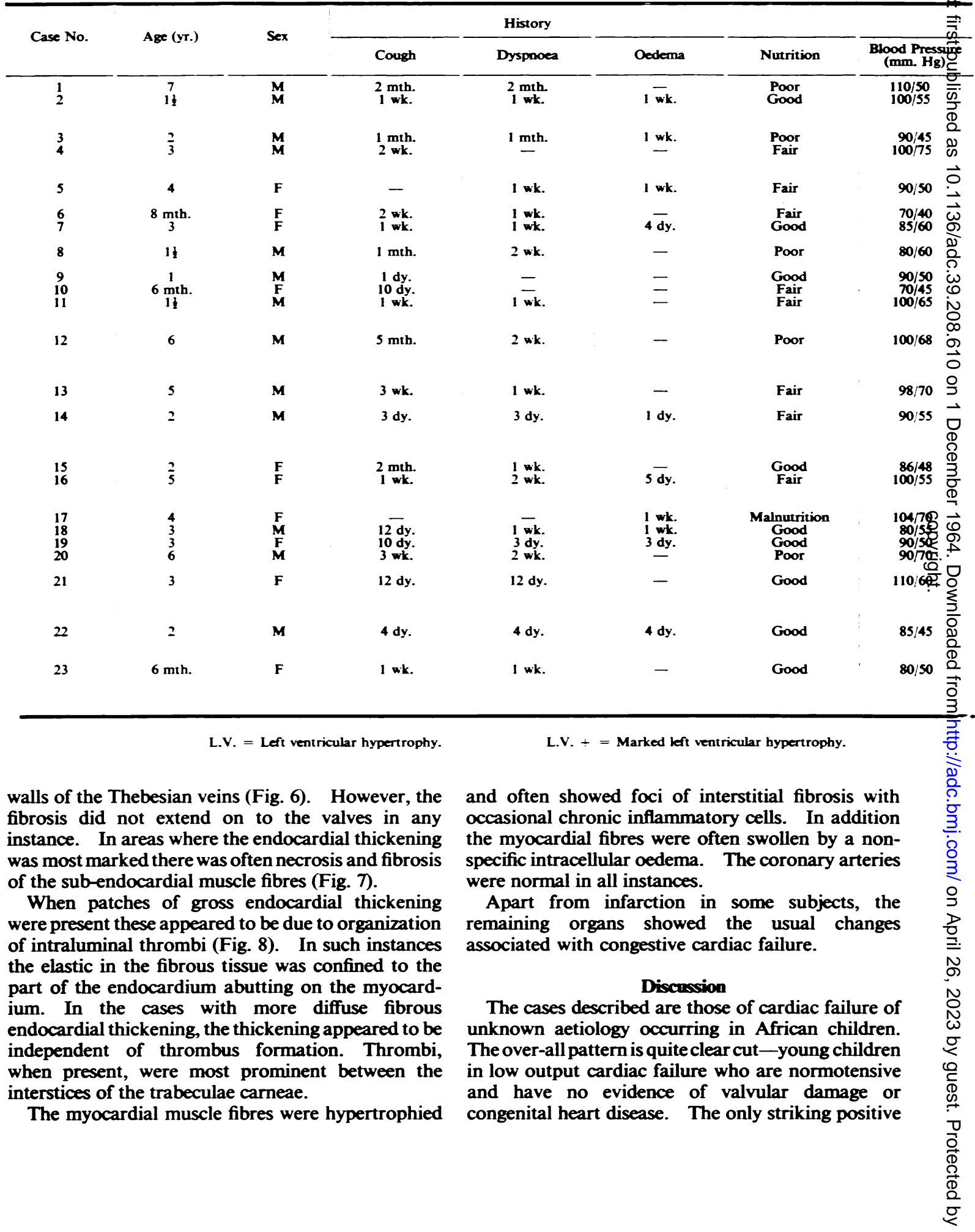




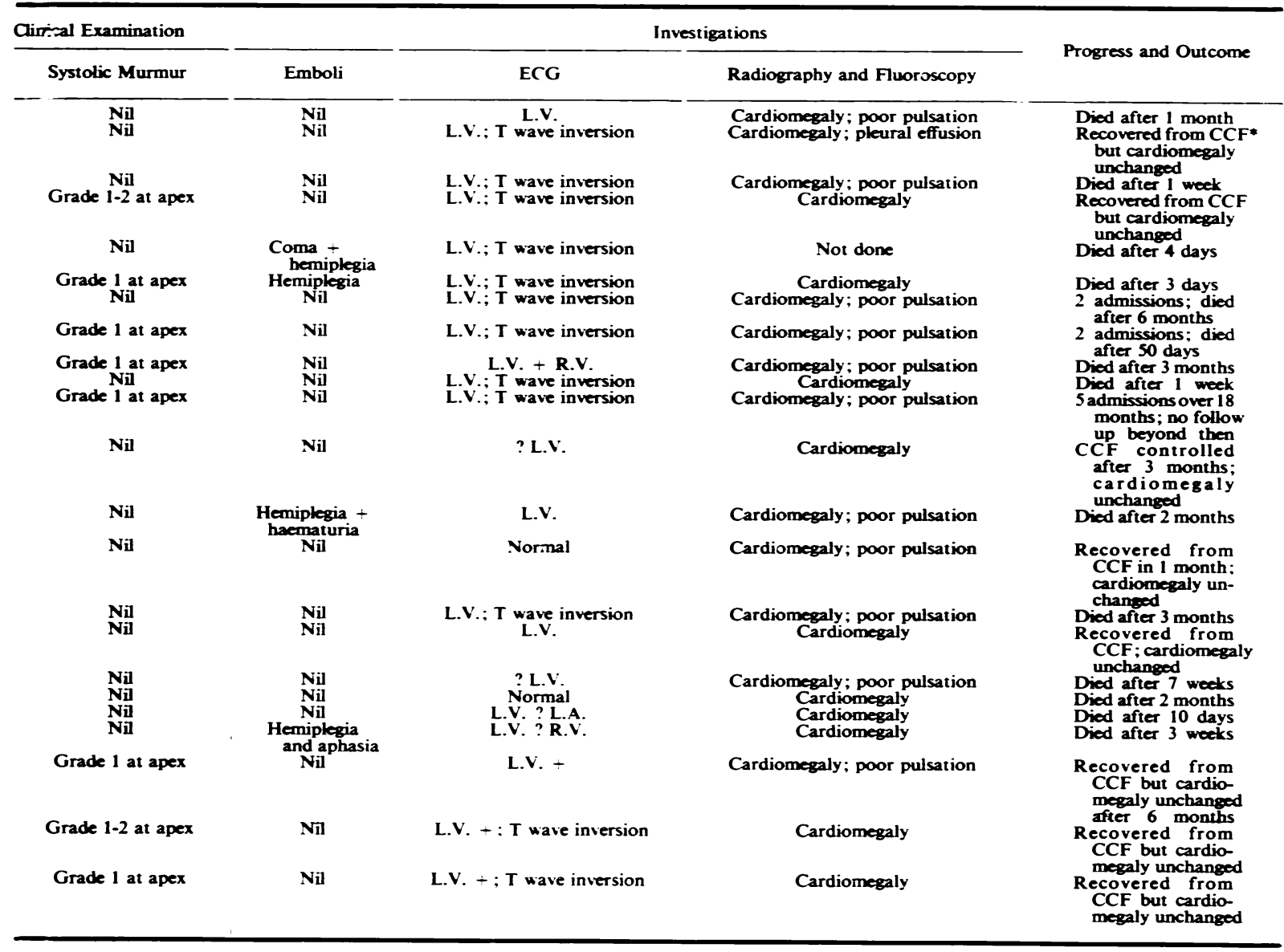

pathological feature is that of endocardial fibroelastosis with cardiac thrombi and emboli in some of the cases. It is of interest to compare these cases with infantile endocardial fibroelastosis as it is seen in other parts of the world. The vast majority of authors agree that infantile endocardial fibroelastosis is in fact a disease of infancy usually presenting within the first six months of life with death usually occurring in the first year (Hill and Reilly, 1951; Gowing, 1953; Blumberg and Lyon, 1952; Nadas, 1957; Fisher, 1962). Many authors describe an association with congenital heart disease particularly patent foramen ovale, bicuspid aortic valve, coarctation of the aorta, and persistent ductus arteriosus (Gowing, 1953; Lambert, 1955; Kelly and Andersen, 1956; Edmonds and Seelye, 1951; Gross, 1941;
Nadas, 1957; Craig, 1949). Some of these authors are stimulated to conclude that the abnormality is a developmental defect (Craig, 1949; Nadas, 1957) and probably of genetic origin (Fisher, 1962). Lambert and Vlad (1958), however, who report 27 cases seen over a 25-year period in the Childrens Hospital in Buffalo state that the condition may occur at any time in childhood and that the process may extend on to the valvular endocardium producing aortic stenosis and mitral incompetence.

Our cases do not present the picture of infantile endocardial fibroelastosis as generally seen elsewhere: only 3 presented below 1 year of age; none had associated congenital heart lesions; and none had valvular involvement secondary to the fibroelastosis. In addition cardiac thrombi and emboli were not 


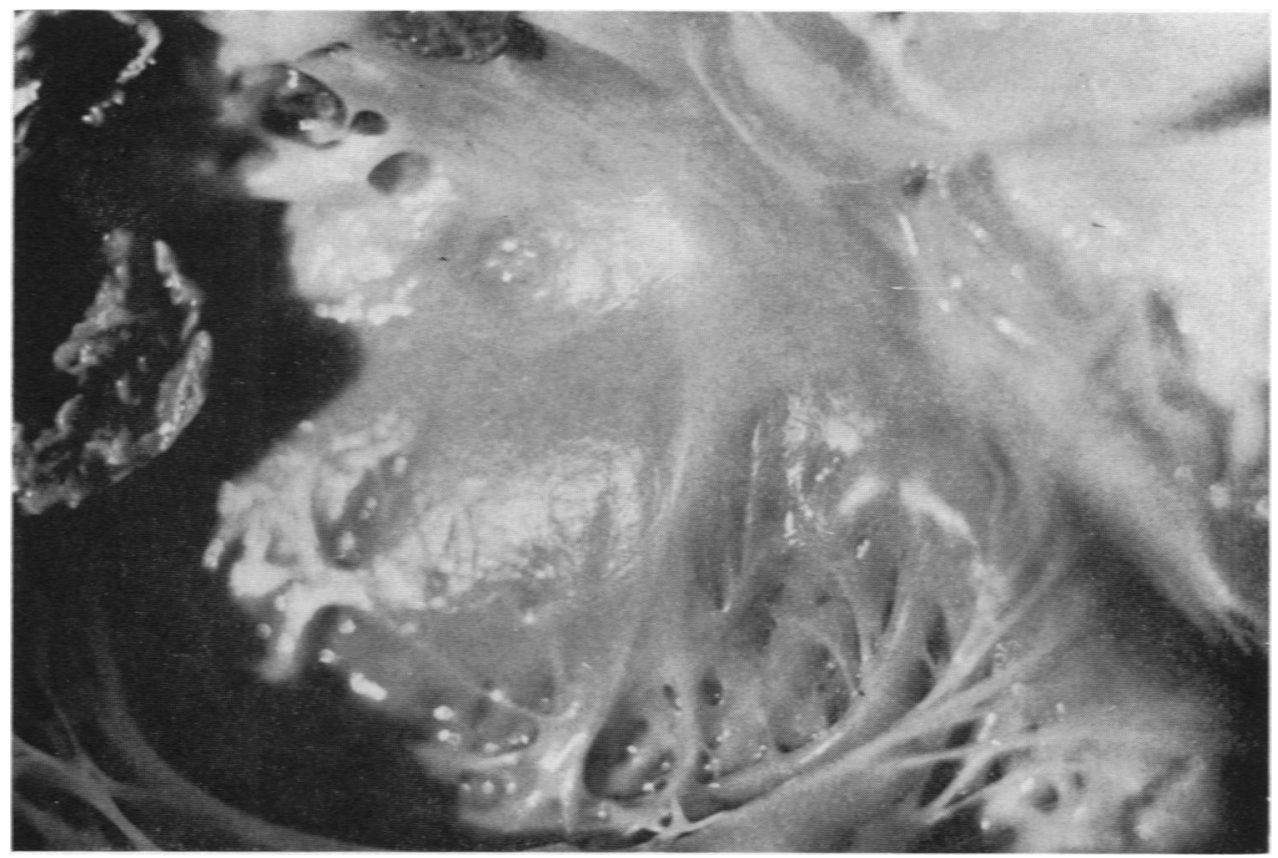

Fig. 3.-Fibrous thickening of endocardium in a 2-year-old boy. A large thrombus is also seen on the left.

features of the cases reported elsewhere while these were quite common in our cases. There is no doubt that our cases are essentially similar to those reported in adults in South Africa and now termed cryptogenic heart disease. It is therefore likely that the aetiology and pathogenesis are similar. As the aetiology is unknown, views on development of this type of heart failure must be largely speculative. Becker et al.

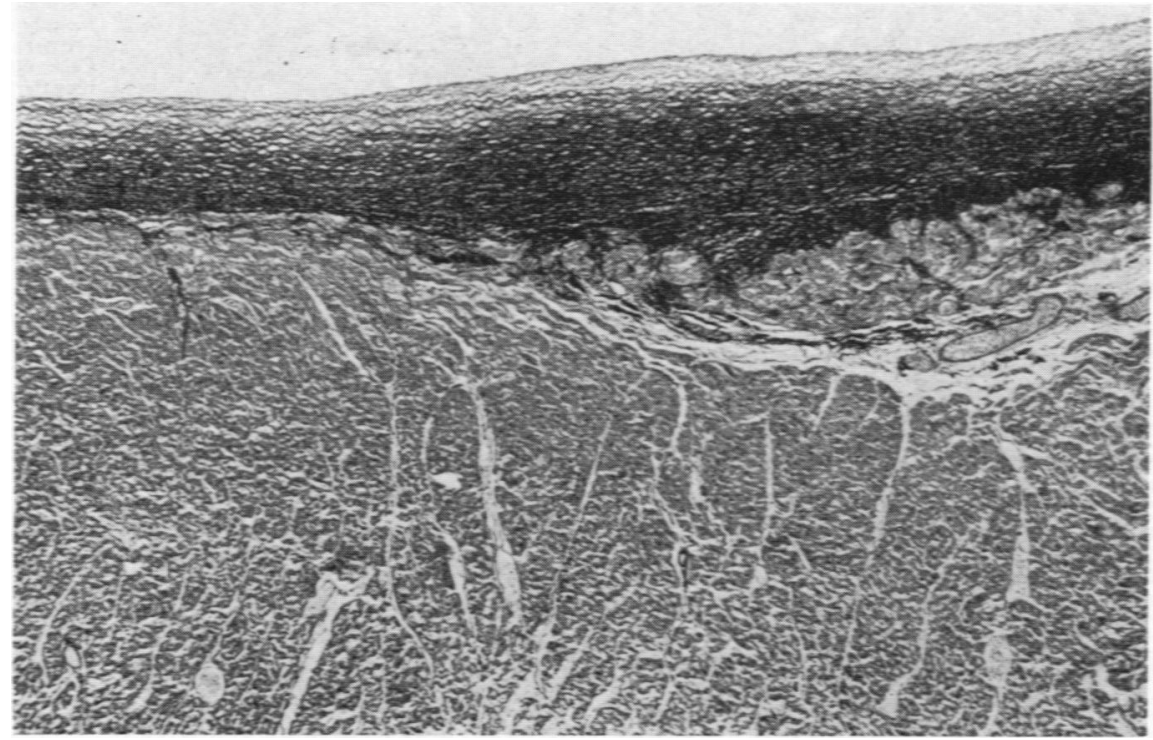

Fig. 4. - Fibreclastosis of endocardium in a boy of 6 years. Note that the elastic is more prominent nearest the myocardium. (Masson. $\times 37$ ). 


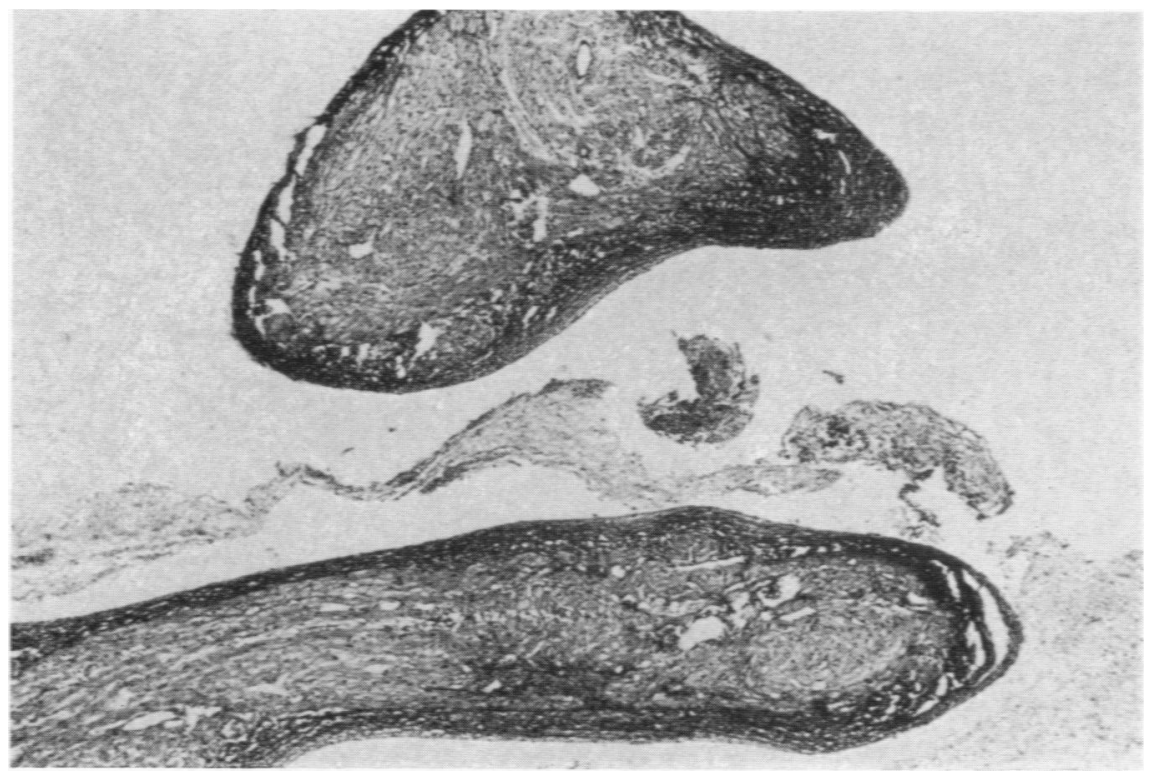

Fig. 5.-Trabeculae carneae encased in fibroelastotic tissue in a boy of 7 years. (Masson. $\times 37$ ).

(1953) suggest that it is primarily endocardial and put forward an auto-immune basis for the condition. Higginson et al. (1960) feel that the primary dysfunction is myocardial, the endocardial lesions being secondary. This view receives support from the studies of Black-Schaffer (1957) who suggests that the endocardial changes are a response to cardiac dilatation and that in fact the sclerotic endocardium is a support rather than an impediment to myocardial function. An additional factor accounting for some

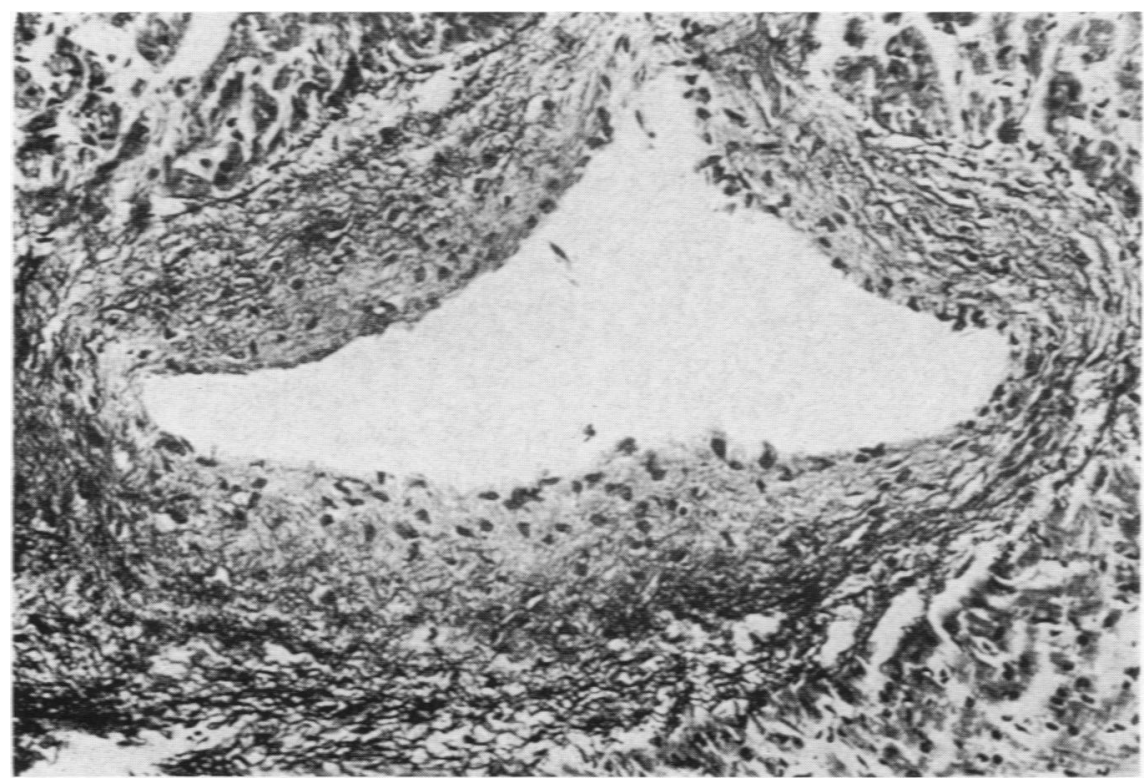

Fig 6 -Intimal thickening of Thebesian vein. same case as Fig. 5. (Hacmatoxylin and cosin. $\times 164$. 


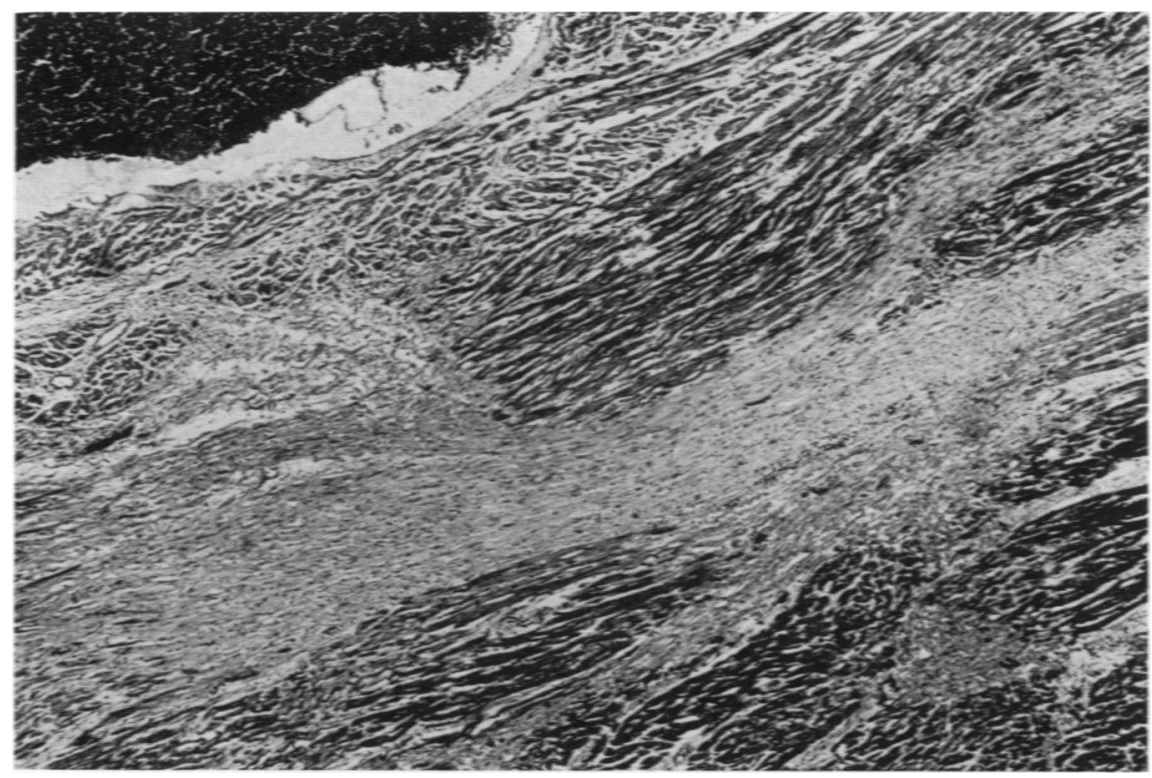

Fig. 7.-Marked myocardial fibrosis, same case as Fig. 5. (Haematoxylin and cosin. $\quad \times$ 37.)

of the endocardial changes which certainly applied in our cases, is that of superimposed mural thrombosis. Organization of these thrombi produces marked endocardial fibrosis. This is usually seen where stasis is most likely, i.e. in the apices of the ventricles and between the interstices of the trabeculae carneae.

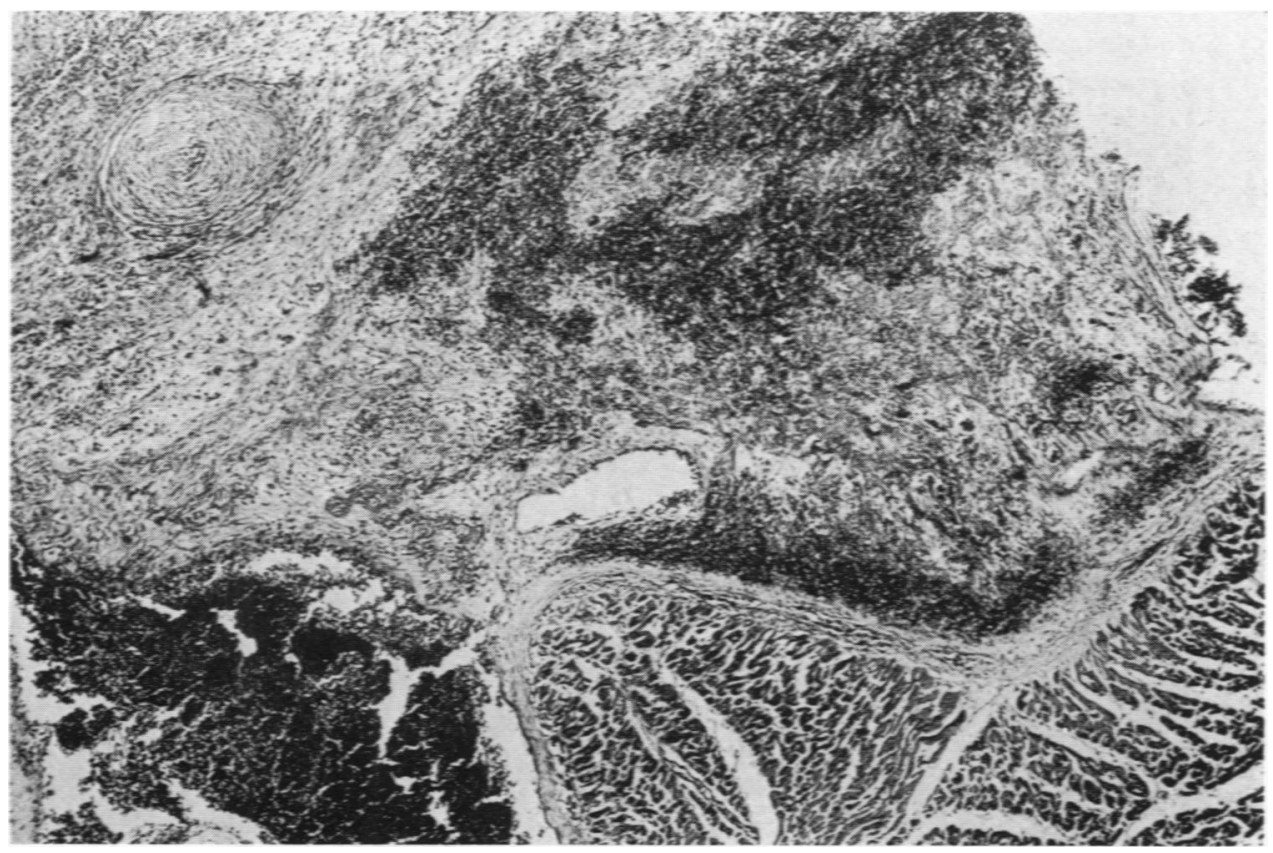

Fis. 8. - Gross fibrous endocardial thickening secondary to organization of thrombi in a girl of 5 years. (Haematoxylin and cosin. $\times 40$. 
The endocardial thickening involves the arterioluminal and Thebesian veins and causes an ischaemia of the inner third of the myocardium, which is nourished from the lumen of the heart via these vessels.

The primary aetiology, too, is obscure. There is no evidence that nutritional factors or infections are significant. As in all conditions occurring predominantly in Africa and of unknown aetiology, the possibility of herbalists' medicines must be considered, but evidence of this was lacking in our patients. That chemical agents can cause a somewhat similar picture is established, for intestinal argentaffin carcinomas with metastases secrete 5-hydroxytryptamine, and this may cause endocardial fibrosis and valvular involvement of the right side of the heart (MacDonald and Robbins, 1957). McKusick (1956) has described a case of carcinoid tumour associated with a right-to-left shunt through a patent foramen ovale where the left side of the heart was also affected. In view of the predominance of the lesion on the left side of the heart in our cases, it is conceivable that if a chemical agent is involved it may be an inhalant. This is an avenue to be explored.

For the moment, however, the aetiology remains unknown and cardiomyopathy of unknown origin in African children remains the most accurate descriptive term.

\section{Summary}

Twenty-three cases of cardiomyopathy in African children are described. The relation of this condition to infantile fibroelastosis and to cryptogenic heart disease in African adults is discussed.

The pathogenesis and possible aetiological factors are briefly discussed.

We wish to thank the Superintendent of Baragwanath Hospital for permission to submit this paper for publication and the Director of the South African Institute for
Medical Research for facilities granted. In addition we thank Mr. Ulrich for the photographs.

\section{Referesces}

Altman. H.. and Stein. H. (1956). Idiopathic hypertrophy of the heart in African children: A report of four cases. Brit. med. J. 1.1207.

Becker. B. J. P.. Chatgidakis. C. B., and van Lingen. B. (1953) Cardiovascular collagenosis with parietal endocardial thrombosis: a clinicopathologic study of forty cases. Circulation. 7. 345

Bedford. D. E., and Konstam. G. L. S. (1946). Heart failure of unknown etiology in Africans. In Proceedings of the Cardiac Society of Great Britain and Ireland. Brit. Heart J.. 8. 236.

Black-Schaffer. B. (1957). Infantile endocardial fibroelastosis. A. M. A. Arch. Path. 63. 281.

Blumberg. R. W.. and Lyon. R. A. (1952). Endocardial sclerosis. A. M. A. Amer. J. Dis. Child. 84. 291.

Craig. J. M. (1949). Congenital endocardial sclerosis. Bull. int. Ass. med. Mus.. 30. 15.

Davies. J. N. P. (1948). Endocardial fibrosis in Africans. E. Afr. med. J.. 25. 10.

Edmonds, H. W.. and Seelye. W. B. (1951). Endocardial sclerosis Review of changing concepts with reports of six cases. Pediatrics. 7,651 .

Fisher. J. H. (1962). Primary endocardial fibroelastosis. A review of fifteen cases. Canad. med. Ass. J.. 87. 105.

Gillanders. A. D. (1951). Nutritional heart disease. Brit. Heart J. $13,177$.

Gowing. N. F. C. (1953). Congenital fibro-elastosis of the endocardium. J. Path. Bact.. 65. 13.

Gross. P. (1941). Concept of fetal endocarditis: A general review with report of an illustrative case. Arch. Path., 31, 163.

Higginson, J., Isaacson. C.. and Simson. I. (1960). The pathology of cryptogenic heart disease. A study of the pathological pattern in eighty cases of obscure heart failure in the South African Bantu negro. A.M.A. Arch. Path., 70. 497.

Hill. W. T., and Reilly. W. A. (1951). Endocardial fibroelastosis. A.M.A. Amer. J. Dis. Child. 82. 579.

Kelly. J., and Andersen. D. H. (1956). Congenital endocardial fibro-elastosis; clinical and pathologic investigation of those cases without associated cardiac malformations including report of two familial instances. Pediatrics. 18. 539.

Lambert. E. C. (1955). Acyanotic conditions with normal pulmonary blood flow. In Congenital Heart Disease: Rep. 14th M. and $R$. Pediat. Res. Conf. 1954. p. 75. M. \& R. Laboratories, Columbus. Ohio.

- and Vlad. P. (1958). Primary endomyocardial disease. Pediat. Clin. N. Amer.. 5. 1057.

MacDonald. R. A., and Robbins. S. L. (1957). Pathology of the heart in the carcinoid syndrome. A. A. Arch. Path. 63. 103.

McKusick, V. A. (1956). Carcinoid cardiovascular disease. Bull. Johns Hopk. Hosp.. 98.13.

Nadas, A. (1957). Pediatric Cardiology. Ist ed. Saunders. Philadelphia. 